\title{
The dark and the bright side of power: implications for the management of business-to-business relationships
}

Vera Belaya ${ }^{1}$ and Jon Henrich Hanf ${ }^{2^{*}}$

\footnotetext{
* Correspondence: jon-hanf@hs-gm.de ${ }^{2}$ Geisenheim University, Geisenheim, Germany

Full list of author information is available at the end of the article
}

\begin{abstract}
The importance of power is underlined by many scientists who view it as a key behavioral construct. Power distinguishes itself as an effective tool in coordinating and promoting harmonious relationships, solving conflicts, and enhancing performance. An important challenge is to determine what role power plays in managing businessto-business relationships with specific attention to coordination and cooperation. The aim of our work is to investigate the role of power in business-to-business relationships to work out a strategy that enables managers to select an effective mix of power mechanisms. We work out and test a theoretical model of the effects of power on cooperation and coordination in business-to-business relationships and discuss possible managerial implications. To verify our research hypotheses, we conduct expert interviews via telephone about relationships of international food processing companies with their suppliers in Russia.
\end{abstract}

Keywords: Business-to-business relationships, Supply chain management, Power, Focal company

\section{Background}

A crucial question in supply chain management (SCM) is how to align the actions and interests of the multitude of involved companies (Ellram and Cooper 1990; Mentzer et al. 2001). In this context, a huge body of literature deals with trust as an appropriate tool (Bachmann 2001; Belaya et al. 2015; Gulati 1995; Jones and George 1998). However, taking a look at the agri-food business, most often supply chains consist of a powerful retailer or processor coordinating various less powerful suppliers and/or buyers. In such an environment, trust is often non-existent and very hard to establish, whereas power ${ }^{1}$ is "naturally" there (Cox 2001a; Maloni and Benton 2000; Reve and Stern 1979; Wilkinson 1973). However, the question arises whether power can be used to align the interests and actions of the various actors.

Several studies on marketing channels have shown that channel power has a significant impact on the buyer-supplier relationship (Chatziaslan et al. 2005; Etgar 1978; Gaski and Nevin 1985; Lee 2001; Liu and Wang 2000; Skinner et al. 1992). The role of power is crucial in the sense that it can seriously hamper cooperation (Hingley 2005; Kumar 2005; Sodano 2006). On the other hand, Cox (2001b) stated that power can be used very effectively to achieve a better deal between buyers and suppliers in supply

(C) 2016 The Author(s). Open Access This article is distributed under the terms of the Creative Commons Attribution 4.0 International License (http://creativecommons.org/licenses/by/4.0/), which permits unrestricted use, distribution, and reproduction in any medium, provided you give appropriate credit to the original author(s) and the source, provide a link to the Creative Commons license, and indicate if changes were made. 
chains. Therefore, the ability to use power to influence other supply chain actors distinguishes itself as an excellent tool for coordinating and promoting harmonious relationships, solving conflicts, and enhancing performance of the whole network and its members. The biggest advantage of using power could be its commanding nature which is perfectly suited for completing specific tasks in SCM.

In this vein, the actual role of power in business-to-business relationships has been treated in contrasting ways in the literature. For many decades, there has been a discussion about the positive (bright side) and negative (dark side) aspects of power (Craig and Gabler 1963). Intriguing and important research questions have arisen regarding how to distinguish among and deal with the two sides of power to avoid problems and how to use power as an effective tool for supply chain management.

Our work aims to investigate the role of power in business-to-business relationships to develop a strategy that enables supply chain managers to select an effective mix of power mechanisms. We look at both views presented in the literature-positive and negative-and present a conceptual framework on how the different aspects of power can be used as mechanisms in chain management. Chain management consists of both the alignment of interests (cooperation) and the alignment of actions (coordination) (Hanf and Dautzenberg 2006), so we explicitly discuss the positive and negative effects of power on cooperation and coordination issues.

To do so, we critically examine the existing literature and elaborate on the role of power in supply chain relationships. We work out and test a theoretical model of the effects of power on cooperation and coordination and discuss possible managerial implications of using power as an effective tool for promoting SCM. To verify our research hypotheses, we conducted expert interviews via telephone about relationships of international food processing companies with their suppliers in Russia. We have deliberately chosen Russia because many international food retail and food processing companies earn a significant share of their revenue there. It is observed that by going abroad, retailers as well as branded food processors export their supply chain management concepts into new markets, both in the sense of enhanced efficiency and in the sense of global chain quality concepts. Due to the tightening of quality standards and the need to work together with suppliers, one of the main consequences is the establishment of tightly coordinated chain organizations (Belaya and Hanf 2010).

\section{The two sides of power in business-to-business relationships}

The previous research results about power effects on exchange relationships are very contradictory. We follow the definition of power by French and Raven (1959), who state that power is "the ability to manage the perceptions of the other party." This definition suits the context of the business-to-business relationships specifically because it implies that the more powerful firm can use power to manage the relationship with its business partners. However, talking about power in the generic sense is not enough. Rather, it is necessary to be specific about the nature of power structures to understand how power is used (Kumar 2005). Furthermore, because the actual effect of power depends on its source (French and Raven 1959), we examine its effects in terms of different power bases using the expanded classification of power bases (French and Raven 1959) by Raven and Kruglanski $(1970)^{2}$ : coercive power, reward power, expert power, informational power, legitimate power, and referent power. 


\section{The dark side of power}

The dark side of power is noted by a number of authors who view the concept of power as alien to the effective workings of exchange relationships and success and state that power negates cooperation (Bretherton and Carswell 2002; Doney and Cannon 1997). Naudé and Buttle (2000) express the common view of power as a negative influence and unhelpful in the building of relationship quality, an area in which the most important cited attributes of a good supply chain relationship are trust, integration, mutual understanding of needs, profit, and satisfaction. Kumar et al. (1998) also view power as the antithesis of trust. Many authors state that over time, the firm with the power advantage consistently abuses the other firm (Stern and Reve 1980) or that the manufacturer exploits the weaker suppliers to obtain superior economic returns (Dore 1983; Perrow 1970). Johnsen and Ford (2001) posit that according to the nature of power relationships, more powerful actors attempt to control the resources of the less powerful actors and limit their ability to take advantage of new opportunities, such as the development of new international markets and customer relationships. Some studies emphasize the necessity for symmetry and mutuality to foster longer-term relationships, while power asymmetries are associated with less stability and more conflict and are considered to be detrimental to sustaining a business relationship (Ganesan 1994; Rokkan and Haugland 2002). According to Kähkönen and Anni-Kaisa (2014), the relationships between buyers and sellers are mostly uneven. They state that buyers have usually more power and relationships of balanced power are rather rare.

\section{Negative effect of power on the alignment of interests (cooperation)}

Some researchers have been specific about the nature of power and argued that one who holds a high level of power will exploit the other party by frequently using relatively coercive influence strategies (Bannister 1969; Robicheaux and El-Ansary 1975; Stern and El-Ansary 1972). For example, one might use power to negotiate lower costs, higher quality, delivery times, and special exigencies (Maloni and Benton 1997), which is considered to be detrimental to the weaker actor (Stolte and Emerson 1976; Thompson 1967). Therefore, power imbalance in supply chain relationships creates opportunities for more powerful firms to act opportunistically by exercising coercion, which may ultimately undermine the trust within the relationship (Belaya and Hanf 2012). One likely consequence is that when one party is threatened by the imbalance of power, that weaker party will be more likely to seek alternative alliances (Ireland and Webb 2007) and the power holder may fail to reach its long-term goals. In other words, coercion is the classical example of the negative side of power. Exercising power against other members of the supply chain might provide short-term benefits for the focal organization but ultimately reduces its success in the long term (Cousins 2002). However, most of the studies on coercion measure the direct effects on the cooperating partners. The negative view on its effects on cooperation is altered if the indirect effects are taken into account (Fehr and Gächter 2002; Walter 2011). If in a group of cooperating actors a known free rider receives a punishment he deserves, the overall cooperativeness within the group increases (Carlsmith 2006; Carlsmith et al. 2002). Furthermore, in the context of deterrence, possible punishments help to avoid free riding (Falk et al. 2005; Fehr and Gächter 2000; Guzman et al. 2007). Etgar (1976) states that expert, referent, and legitimate power sources may be less effective than coercive and reward power 
sources because they are less flexible and are often viewed as being unrelated to specific performance by chain members. Furthermore, their effectiveness may decline over time. As for legitimate power, it is difficult to predict the reaction of a weaker party because the latter may choose not to enter the relationship if it feels intimidated. French and Raven (1959) state that legitimate power stems from internalized values which dictate that there is a legitimate right to influence and an obligation to accept this influence. Giebels et al. (1998) express the opinion that when there is a power imbalance, there appears to be difficulty in fostering the information flow, which is a precondition for the successful negotiation of an exchange. Gaski (1986) argues that the use of informational power involves manipulative aspects. Stern and El-Ansary (1992) also support the statement that informational power is likely to have a negative effect on cooperation in distribution channels. They argue that channel participants do not necessarily view each other as partners, but rather as rivals, and therefore, the use of informational power in this case is not well received. In the literature, reward power has been seen as having a mixed effect on the buyer-supplier relationship (Maloni and Benton 2000; Zhao et al. 2008). It was suggested that reward power has a positive effect when the culture supports cooperative and supportive relationships. However, it can be assumed that reward power may have an element of coercion in it and therefore have the same effect as coercive power on relationships. Overuse of reward power is likely to damage relational norms (Boyle et al. 1992) and cooperation (Skinner et al. 1992). Furthermore, Goldsmith and Dhar (2013) showed that negatively rather than positively framed incentives motivate people to work harder.

\section{Negative effect of power on the alignment of actions (coordination)}

According to Mohr et al. (1996), coordination between parties is enhanced when a more standardized business format is applied. This idea is also mirrored in the studies of Lusch and Brown (1996) and Jap and Ganesan (2000), who state that contracts, which present clear guidelines and specify the rights and obligations of both parties, improve coordination. Clemons and Row (1993) showed that although it might seem that information could help improve coordination, the weaker party might not necessarily respond positively to the coordination attempts of the power holder, who is using information and expertise as a tool of its bargaining power.

Lee et al. (1997) also support the idea that coordination is different from information sharing. Information can be shared, but there may not be any alignment in terms of incentives, objectives, and decisions, as is required for coordination. Coordination exists for the purpose of decision-making in the best interest of the system (Zhao et al. 2002); however, some agents may have information which they do not want to share with the principal.

\section{The bright side of power}

Many authors state that power appears to be synonymous with oppression, coercion, and force, despite the fact that such negative approaches are just one aspect of power (Duke 1998). Despite criticism of power as the antithesis of trust, Kumar et al. (1995) contend that trusting partnerships can be built between unequals but only if the powerful party treats the weaker, vulnerable party fairly. A body of literature states that power can be used by the focal actor as an effective tool in coordinating and promoting harmonious relationships, solving conflicts, and, therefore, enhancing the performance of 
the whole network as well as its individual members. Some authors who have emphasized power's positive aspects argue that possession of power does not suggest exploitation or frequent use of coercion (Blau 1964; Stern and Heskett 1969). Power does not necessarily imply coercion or use of force; it may involve any degree of compulsion, from the gentlest suggestion to absolute domination (Beier and Stern 1969).

Others argue that power is vital because it can take the relationship out of the realm of chance and give it purpose, order, and direction (Dwyer et al. 1987; Kumar 2005). Condliffe (1944) says that power, including the possible use of force, is not necessarily evil but may be used to achieve moral purposes. Other researchers have emphasized the role of power in the effective coordination of the exchange relationship, rather than its potential for exploitation. Blau (1964) provides the underlying foundation for this viewpoint. In a marketing channel context, Stern and Heskett (1969) theorize that the exercise of power can have a positive role in the achievement of integration, adaptation, and goal attainment within the channel system. Bierstedt (1950) suggests that power stands behind every association and sustains its structure; without power, there is no organization and no order.

\section{Positive effect of power on the alignment of interests (cooperation)}

The exercise of non-coercive power does not include any aggressive elements that may produce friction in the relationship. On the contrary, it fosters a relatively high level of agreement between the interacting parties because to a large extent, it contains the inherent desirability of performing certain actions (Frazier and Summers 1984). Moreover, the use of non-coercive power helps to increase financial and social benefits, through, for example, the offering of financial rewards, provision of assistance, and access to specialized information (Wilkinson 1979). Therefore, this type of power can help to promote common interests and collective goals within the relationship, as well as enhance a friendly and constructive atmosphere (Gagalyuk et al. 2013).

Scientists found that firms exposed to exercise of influence by a "partner firm" are more satisfied with the relationship if non-coercive power, rather than coercive power, is used (Hunt and Nevin 1974; Lusch 1977). Scientists also found that non-coercive power sources are inversely related and coercive sources are directly related to the existence of interfirm conflict (Lusch 1976; Wilkinson 1981) and that the use of noncoercive power sources is positively related to the performance of the firm that is exposed to exercise of influence by the "partner firm" (Sibley and Michie 1981). Furthermore, scholars who have studied power suggested that non-coercive power sources provide better alternatives for enhancing the satisfaction of less powerful trading partners (Hunt and Nevin 1974; Lusch 1976). The study conducted by Lee and Low (2008) indicates that legitimate power showed positive relationships with satisfaction. Legitimate power originates from a given position or existing norms or laws, so the supplier may take the protection offered by a buyer's legitimized powerful position for an additional advantage. Dapiran and Hogarth-Scott (2003) emphasize that cooperation comes from the use of expert and referent power.

Because referent power was ranked highest among other power bases in connection to satisfaction (Lee and Low 2008), and cooperation has been found to go hand in hand with satisfaction (Gaski 1984), we suppose that a buyer's positive image and good reputation will foster cooperation. Suppliers would also be more willing to comply with the 
requirements of internationally recognized retailers and fulfill their commands. As noted by Eyuboglu and Atac (1991), depending on the channel, informational power will have different effects on cooperation. Gaski (1986) states that partner perceptions (such as expert, referent, and legitimate power sources) are managed through reward and coercive power sources to create harmonious and enduring interorganizational exchange relationships.

\section{Positive effect of power on the alignment of actions (coordination)}

Some authors see a positive side of power in promoting coordination in supply chain relationships. Bachmann (2001) states that power can be regarded as a mechanism for coordinating social interactions efficiently and allows relatively stable relationships to develop between cooperating social actors. Stern and El-Ansary (1992) assert that channel members use power to determine who will undertake which marketing activities, coordinate the performance of these tasks, and manage conflict among themselves. The positive effect of legitimate power has been observed as contributing to the effective coordination of exchange relationships as the distribution of power has become legitimate over time (Frazier and Antia 1995; Kalafatis 2000). When a customer uses reward or coercive power, the supplier is extrinsically motivated to commit to it and comply with the customer's requirements to achieve favorable outcomes (Zhao et al. 2007).

\section{Framework of the effects of power on cooperation and coordination}

Having examined the existing literature, our findings illustrate that power has two sides that play an important role in supply chain management. Based on the literature, we assume that both sides of power could be used effectively to achieve cooperation and coordination among supply chain actors. Thus, we develop the theoretical model of the effects of power on cooperation and coordination and formulate research hypotheses H1a-H6b with specific attention to cooperation and coordination issues (Fig. 1).

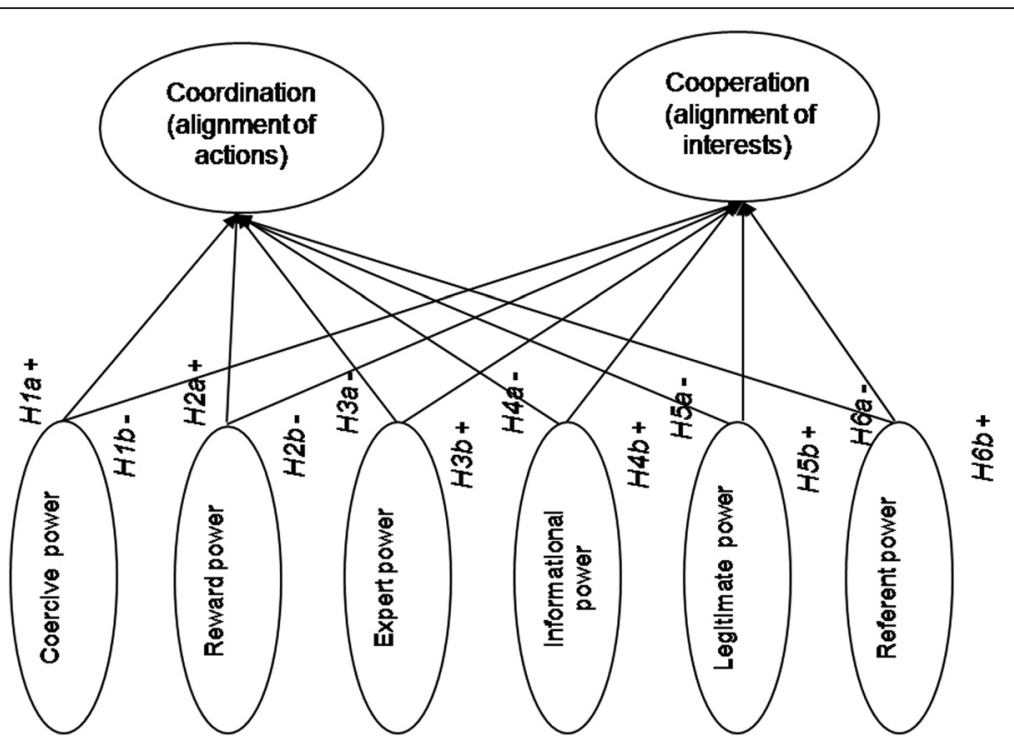

Fig. 1 Theoretical model of the effects of power on coordination and cooperation. Source: own illustration 
Researchers agree that the frequent use of power to force other partners into action will lead to the exploitation of the target (Bannister 1969; Robicheaux and El-Ansary 1975), which is detrimental to the quality of relationship (Gellynck et al. 2011; Stolte and Emerson 1976; Thompson 1967). Hunt and Nevin (1974) indicated that coercive power is related positively to intrachannel conflict and inversely to dealer satisfaction, whereas non-coercive power exhibits the opposite relationships. Exercising coercive power against other members of the supply chain might have short-term benefits for the focal organization but reduces its success in the long term (Cousins 2002). However, Stern and El-Ansary (1992) asserted that channel members may use power to determine who will undertake which marketing activities, coordinate the performance of these tasks, and manage conflict among themselves. Hamner and Organ (1978) suggested that punishment is one of the most readily available means for shaping (and maintaining) the behavior of subordinates. Other authors viewed coercive power as a mechanism for allowing relatively stable relationships to develop between cooperating social actors (Bachmann 2001; Stern and El-Ansary 1992).

Within a supply chain, the perceived use of coercive power will positively affect coordination (H1a) and negatively affect cooperation (H1b).

Gaski (1986) stated that it is through reward and coercive power that partner perceptions are managed to create harmonious and enduring relationships. If the use of power is based on genuine rewards, the supplier will be willing to accept them and enter a trusting relationship. If a buyer continuously uses reward power to give rewards to its suppliers who comply with its quality standards and deliver on time, it can promote cooperation and generate trust in this relationship. Assuming that reward power provides extrinsic motivation, which drives partners to comply with the requirements to achieve favorable outcomes (Zhao et al. 2008), it will have a positive effect on coordination. However, the overly frequent use of reward power is likely to damage relational norms (Boyle et al. 1992) and cooperation (Skinner et al. 1992). Therefore, the exaggerated use of reward power may lead to distrust, suspicion, and eventually abstaining from entering a trusting relationship by a target of influence; in other words, if unrealistically high discounts or other offered rewards are unusual for the culture or mentality of the latter, they may be associated with corruption or bad purposes.

Within a supply chain, the perceived use of reward power will positively affect coordination $(\mathrm{H} 2 \mathrm{a})$ and negatively affect cooperation $(\mathrm{H} 2 \mathrm{~b})$.

Expert power is considered to be less effective than coercive and reward power due to being less flexible and unrelated to specific performance of supply chain members (Etgar 1976). In general, the acquisition of special knowledge or technology to achieve a powerful position and the use of expert power formed in this way will contribute to the positive development of cooperation within a supply chain relationship. Expert power is perceived as positive when solicited and given. Offering free advice through an agency and advisory staff as part of project implementation is seen to be a valuable incentive for the target of influence to get involved in the project (Davies et al. 2004). Furthermore, some authors emphasized that consultation and swapping of information might produce expectations of reciprocity and trust (Blau 1964; Coleman 1990). Thus, expert power could be most effective as an influence tactic when the objectives of the person being influenced match those of the leader. 
Within a supply chain, the perceived use of expert power will negatively affect coordination (H3a) and positively affect cooperation (H3b).

Gaski (1986) argued that the use of informational power involves manipulative aspects. Stern and El-Ansary (1992) supported the statement that informational power is likely to have a negative effect on coordination in channels of distribution. They argued that channel participants do not necessarily view each other as partners but rather as rivals. Payan and McFarland (2005) found that information exchange has a lower likelihood of compliance with the requirements of the influencing. As noted by Eyuboglu and Atac (1991), depending on the channel, informational power will have different effects on cooperation. Information exchange could have a positive effect on cooperation, since it not only conforms to but also elevates the level of relationalism between parties (Boyle et al. 1992) and is based on mutual trust (Baldwin 1971; Raven and Kruglanski 1970). We assume that in an environment in which participating parties view each other as partners and not as rivals, informational power will have a positive effect on cooperation because it helps to build trust and enhances positive attitudes toward the long-term channel relationships.

Within a supply chain, the perceived use of informational power will negatively affect coordination (H4a) and positively affect cooperation (H4b).

The study conducted by Lee and Low (2008) indicated that legitimate power showed positive relationships with satisfaction. Effective coordination of exchange relationships has been observed as a positive effect of legitimate power (Frazier and Antia 1995; Kalafatis 2000), and a more standardized business format is applied, such as contracts (Jap and Ganesan 2000; Lusch and Brown 1996; Mohr et al. 1996). Boyce et al. (1992) suggested that in the effective operation of an agreement, it is the spirit rather than the written word that is important. The written word becomes significant when things are going wrong. According to this statement, legal contracts specifying formal written rules and obligations could be a harder form of legitimate power than the cooperative norm, which only refers to unwritten unofficial norms, unofficial values, norms, shared values, rules of conduct, and beliefs that guide actions and behaviors. Regulations and economic incentives play an important role in encouraging changes in behavior, but although these may change practices, there is no guaranteed positive effect on personal attitudes (Gardner and Stern 1996).

Within a supply chain, the perceived use of legitimate power will positively affect coordination ( $\mathrm{H} 5 \mathrm{a})$ and negatively affect cooperation ( $\mathrm{H} 5 \mathrm{~b})$.

Because referent power was ranked highest among other types of power in connection to satisfaction (Lee and Low 2008), and since cooperation has been found to go hand in hand with satisfaction (Gaski 1986), we suppose that the use of a positive image and good reputation will foster the development of cooperation. Dapiran and Hogarth-Scott (2003) emphasized that cooperation comes about through the use of expert and referent power. Suppliers would also be more willing to comply with the requirements of internationally recognized buyers and fulfill their commands. However, high degrees of identification between buyers and suppliers may be associated with less channel control. Referent power might not be sufficient to motivate the target to the implementation of certain tasks because they do not represent an explicit statement of the desired behavior. Therefore, using referent power might not be sufficient to animate the target to the implementation of certain tasks. 
Within a supply chain, the perceived use of referent power will negatively affect coordination (H6a) and positively affect cooperation (H6b).

\section{Methods}

\section{Empirical study of the Russian agri-food business} Data collection

To verify our research hypotheses, we conducted semi-structured, in-depth, expert interviews via telephone about relationships between international food processing and retail companies and their suppliers in Russia from the 31st of March until the 17th of June 2010. The database for the telephone survey was obtained from The Chamber of Commerce and Industry of the Russian Federation and contained 1000 records of contact details about the companies of foreign origin registered in Russia as companies operating in the area of food processing in Russia with at least $10 \%$ of foreign direct investment capital. A total of 97 complete telephone interviews (89 interviews with food processing companies and 8 interviews with retailers) were conducted. ${ }^{3}$

We made a thorough selection of the interviewees who were chosen according to their leading positions to effectively gather relevant information (Blankertz 1998; Merkens 2000; Patton 1990). Specifically, we employed an expert (concentration) sampling (Fritsch 2007; Patton 1990). The people chosen were in positions with a high level of concentration of appropriate information. The applied technique makes particular sense in light of the abovementioned research questions. Before contacting the companies from the database, we made a thorough pretest study by contacting 15 experts from the field of agri-food business and conducting telephone conversations with them. This pretest allowed us to identify potential problems and to revise the proposed questionnaire before starting the actual fieldwork. We started the survey after receiving their feedback and improving the questionnaire. The questionnaire was designed in three languages (Russian, English, and German) to allow the experts speaking different languages to participate in the questionnaire. Because the majority of the respondents wanted to be treated anonymously and did not give their permission to tape-record the interviews, they were logged in written form.

The survey tool contained three main sections (Section I: Mechanisms for managing agri-food supply chains, Section II: Problems of managing agri-food supply chains, and Section III: Information about the interviewee and his business partners). The questions were grouped according to the thematically connected blocks within each section. We applied a four-point scale (e.g., frequency of use of influence strategies: 1- "not at all," 2-“seldom," 3-“often," 4-“very often"; the state of satisfaction with coordination and cooperation aspects: 1-"very dissatisfied," 2-"dissatisfied," 3-"satisfied," 4-"very satisfied"). The answer option "don't know" was also given to increase the reliability of the answers. One of the first questions asked was "Do you feel responsible for coordinating the supply chain of this product ("from the field to the fork")?." Two answer options were given: "yes" and "no." We only used companies that answered "yes" as we selected for focal companies which were the target of our research.

To test our model, we used the partial least squares (PLS) technique for structural equation modeling and applied the SmartPLS software 2.0.1 (Ringle et al. 2005). 


\section{Results and discussion}

According to Hair et al. (2006), an item is considered insignificant and removed from the model if its factor loading is less than 0.4. The remaining indicators represent more than $50 \%$ of the share of the variance of each indicator in respect to the corresponding latent variable and can be considered as the most reliable. Based on this criterion, we removed 23 indicators from the initial model to achieve the indicator reliability for our model (Fig. 2).

The internal consistency of the model was assessed by calculating the Cronbach $\alpha$ and composite reliability (Table 1). Cronbach's $\alpha$ is a measure of internal consistency and must not be lower than 0.6. In our case, all variables except for legitimate power have their Cronbach's $\alpha$ within the borders of the advised number. Unfortunately, the measure of Cronbach's $\alpha$ for legitimate power is 0.523 , which is slightly lower than 0.6. Nevertheless, the composite reliability is achieved for this variable as it is for all the other variables. The composite reliability is a measure of internal consistency and must not be lower than 0.6. In our case, it is even better because it is over 0.7. The convergent validity of the model was assessed by calculating the average variance extracted (AVE) which should be higher than 0.5 (Fornell and Larckner 1981). The variable that does not quite correspond with this rule is cooperation. The measure of AVE for this construct is slightly lower and equals 0.473 .

The next step of our analysis is to evaluate the fit of the structural (inner) model. We do this by assessing discriminant validity by comparing the square root of the AVE with the correlation between the construct and the other constructs (Table 2). The structural model was also evaluated based on the $R^{2}$ values and the significance of the path coefficients using the bootstrap method. Usually, $R^{2}$ values of $0.67,0.33$, and 0.19 can be regarded as substantial, moderate, and weak, respectively (Chin 1998). In model 1, the constructs coordination and cooperation have the values of $R^{2} 0.305$ and 0.332 , which considering the complexity of the research model indicate a good fit (Table 3 ). Following Martinez-Ruiz and Aluja-Banet (2009) to assess the significance of path coefficients, standard errors and $t$ values may be computed by bootstrapping (200 samples; $t$ value $>1.65$ significant at the 0.05 level; $t$ value $>2$ significant at the 0.01 level). We

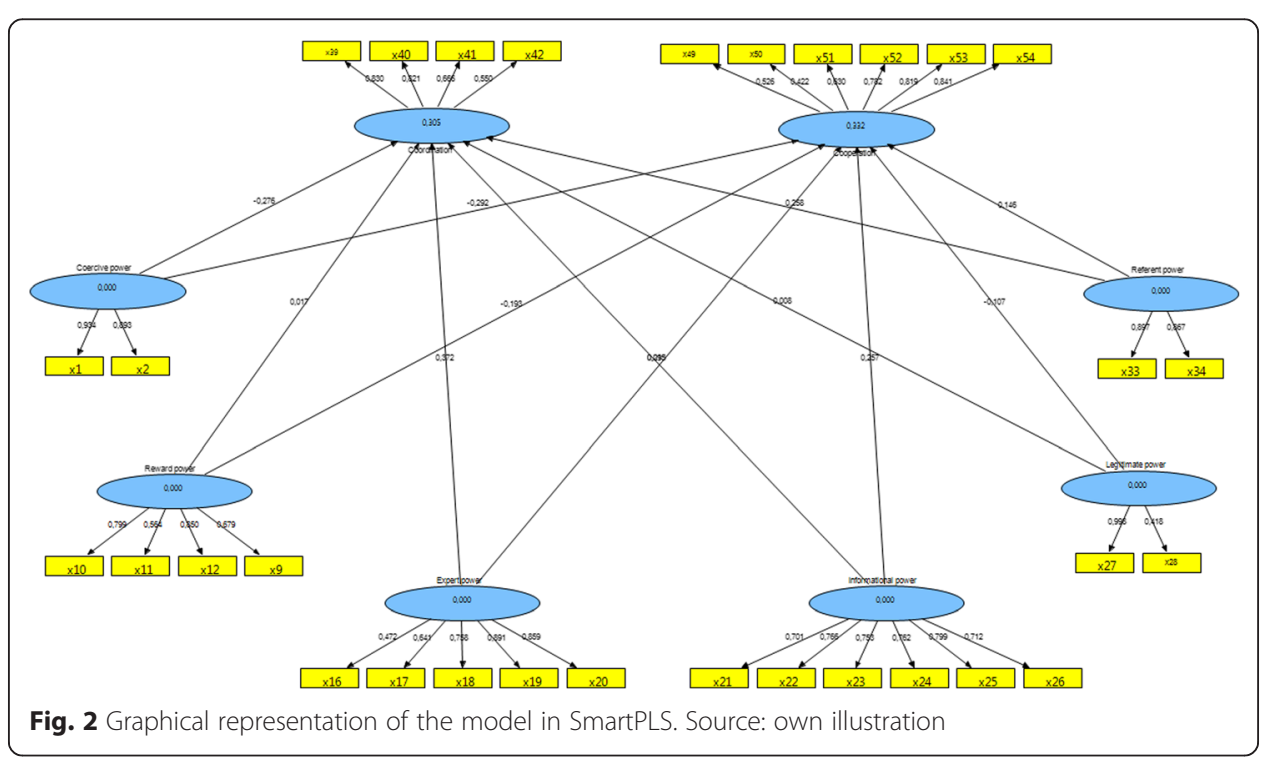


Table 1 Results of the assessment of measurement model: Cronbach's a, composite reliability, and AVE

\begin{tabular}{llll}
\hline Latent variables & Cronbach's $a$ & Composite reliability & AVE \\
\hline COOR & 0.719285 & 0.813111 & 0.527487 \\
COOP & 0.757797 & 0.836368 & 0.473304 \\
CP & 0.805315 & 0.910199 & 0.835268 \\
RWP & 0.734857 & 0.817823 & 0.534618 \\
EP & 0.807736 & 0.852956 & 0.547956 \\
IP & 0.846552 & 0.884829 & 0.561973 \\
LP & 0.523012 & 0.706973 & 0.584865 \\
RFP & 0.715612 & 0.875101 & 0.777990 \\
\hline
\end{tabular}

Source: own calculations

Abbreviations: COOR coordination, COOP cooperation, $C P$ coercive power, RWP reward power, EP expert power, IP informational power, $L P$ legitimate power, RFP referent power

used the method of bootstrapping (sample $=200$ ) to generate $t$-statistics to test the significance levels of standardized path estimates. According to the results, 6 out of 12 hypotheses (H1a, H1b, H3a, H3b, H4b, H6a) were significant and 4 out of 12 hypotheses (H1a, H3a, H4a, H6a) did not have the expected sign. The values were significant and the signs were positive for the following hypotheses: H3a, H3b, H4b, and H6a. The values were significant but the expected sign was different for the following hypotheses: H1a, H3a, and H6a. When the values are significant and the signs are positive, the model provides empirical support of hypothesized effects. Therefore, these hypotheses were supported in our model. If the values are insignificant and the signs are contrary to the assumed effects, the hypotheses are not supported. In our case, the values are insignificant and the signs are contrary to the assumed effects for hypothesis H4a. Therefore, this hypothesis was not supported in our model. The results of hypotheses testing are presented in Table 4.

The knowledge of different power sources is essential to successfully managing business-to-business relationships. Managers should be particularly aware that power, depending on its source, may have different effects on coordination and cooperation.

In line with our observations in the in-depth expert interviews, Hofstede (2001) and Kadochnikov (2004) have shown that there is a positive attitude in the Russian

Table 2 Correlations of the latent variables and the AVE square roots

\begin{tabular}{lllllllll}
\hline & COOP & \multicolumn{1}{l}{ COOR } & CP & EP & IP & LP & RFP & RWP \\
\hline COOP & 0.687971 & & & & & & & \\
COOR & 0.423507 & 0.726283 & & & & & & \\
CP & -0.249700 & -0.181373 & 0.913930 & & & & & \\
EP & 0.375932 & 0.419556 & 0.179414 & 0.740241 & & & & \\
IP & 0.372067 & 0.271215 & 0.128049 & 0.580504 & 0.749649 & & & \\
LP & -0.306813 & -0.248269 & 0.435816 & -0.199264 & -0.158320 & 0.764765 & & \\
RFP & 0.257241 & 0.360260 & 0.086310 & 0.321386 & 0.273676 & -0.209867 & 0.882037 & \\
RWP & 0.085145 & 0.231527 & 0.048065 & 0.423462 & 0.384902 & -0.295605 & 0.260505 & 0.731176 \\
\hline
\end{tabular}

Source: own calculations

Abbreviations: COOR coordination, COOP cooperation, $C P$ coercive power, RWP reward power, EP expert power, IP informational power, $L P$ legitimate power, RFP referent power 
Table 3 Results of the assessment of structural model

\begin{tabular}{|c|c|c|c|c|c|}
\hline Hypotheses & $\begin{array}{l}\text { Effects of latent } \\
\text { variables }\end{array}$ & t-statistics & $\begin{array}{l}\text { Beta (path) } \\
\text { coefficients (b) }\end{array}$ & $\begin{array}{l}\text { Correlation } \\
\text { coefficient }(r)\end{array}$ & $b r$ \\
\hline $\mathrm{H} 1 \mathrm{a}$ & $\mathrm{CP} \rightarrow \mathrm{COOR}$ & 3.142365 & -0.276474 & -0.181373 & 0.050 \\
\hline $\mathrm{H} 1 \mathrm{~b}$ & $\mathrm{CP} \rightarrow \mathrm{COOP}$ & 3.211364 & -0.291692 & -0.249700 & 0.073 \\
\hline $\mathrm{H} 2 \mathrm{a}$ & $\mathrm{RWP} \rightarrow \mathrm{COOR}$ & 0.172568 & 0.016637 & 0.231527 & 0.004 \\
\hline $\mathrm{H} 2 \mathrm{~b}$ & $\mathrm{RWP} \rightarrow \mathrm{COOP}$ & 1.476850 & -0.193422 & 0.085145 & -0.016 \\
\hline $\mathrm{H} 3 \mathrm{a}$ & $\mathrm{EP} \rightarrow \mathrm{COOR}$ & 3.836822 & 0.372217 & 0.419556 & 0.156 \\
\hline $\mathrm{H} 3 \mathrm{~b}$ & $\mathrm{EP} \rightarrow \mathrm{COOP}$ & 2.418828 & 0.292702 & 0.375932 & 0.110 \\
\hline $\mathrm{H} 4 \mathrm{a}$ & $\mathrm{IP} \rightarrow \mathrm{COOR}$ & 0.130923 & 0.014832 & 0.271215 & 0.004 \\
\hline $\mathrm{H} 4 \mathrm{~b}$ & $\mathrm{IP} \rightarrow \mathrm{COOP}$ & 2.736924 & 0.257051 & 0.372067 & 0.096 \\
\hline $\mathrm{H} 5 \mathrm{a}$ & $\mathrm{LP} \rightarrow \mathrm{COOR}$ & 0.078643 & 0.007748 & -0.248269 & -0.002 \\
\hline $\mathrm{H} 5 \mathrm{~b}$ & $\mathrm{LP} \rightarrow \mathrm{COOP}$ & 1.037731 & -0.107228 & -0.306813 & 0.033 \\
\hline H6a & $\mathrm{RFP} \rightarrow \mathrm{COOR}$ & 2.910312 & 0.257730 & 0.360260 & 0.093 \\
\hline $\mathrm{H} 6 \mathrm{~b}$ & $\mathrm{RFP} \rightarrow \mathrm{COOP}$ & 1.588292 & 0.145881 & 0.257241 & 0.038 \\
\hline
\end{tabular}

Source: own calculations

Abbreviations: COOR coordination, COOP cooperation, CP coercive power, RWP reward power, EP expert power, IP informational power, $L P$ legitimate power, RFP referent power

culture toward power and hierarchical orders. Thus, the rejection of our assumption that coercive power can be seen to bring order and discipline into the relationship as well as be effective in changing behavior was unexpected. An explanation might be that the interviewees assessed the direct effects of coercion in a bilateral rather than in a multilateral case. However, as many experiments have shown (e.g., Carlsmith 2006; Fehr and Gächter 2002), particularly for larger groups, coercion in the form of a deserved and justified punishment and/or deterrence can help to avoid free riding. Furthermore, according to our general impression, the respondents were reluctant to speak about the use of coercive power. Therefore, coercive power could have been used in reality more often than the respondents were ready to admit. In spite of these

Table 4 Information about the results of hypotheses testing

\begin{tabular}{lllll}
\hline Hypotheses & Effects of latent variables & Expected sign & Obtained sign & Supported/not supported \\
\hline $\mathrm{H} 1 \mathrm{a}$ & $\mathrm{CP} \rightarrow \mathrm{COOR}$ & + & - & Not supported \\
$\mathrm{H} 1 \mathrm{~b}$ & $\mathrm{CP} \rightarrow \mathrm{COOP}$ & - & - & Supported \\
$\mathrm{H} 2 \mathrm{a}$ & $\mathrm{RWP} \rightarrow \mathrm{COOR}$ & + & + & Supported \\
$\mathrm{H} 2 \mathrm{~b}$ & $\mathrm{RWP} \rightarrow \mathrm{COOP}$ & - & - & Supported \\
$\mathrm{H} 3 \mathrm{a}$ & $\mathrm{EP} \rightarrow \mathrm{COOR}$ & - & + & Not supported \\
$\mathrm{H} 3 \mathrm{~b}$ & $\mathrm{EP} \rightarrow \mathrm{COOP}$ & + & + & Supported \\
$\mathrm{H} 4 \mathrm{a}$ & $\mathrm{IP} \rightarrow \mathrm{COOR}$ & - & + & Not supported \\
$\mathrm{H} 4 \mathrm{~b}$ & $\mathrm{IP} \rightarrow \mathrm{COOP}$ & + & + & Supported \\
$\mathrm{H} 5 \mathrm{a}$ & $\mathrm{LP} \rightarrow \mathrm{COOR}$ & + & + & Supported \\
$\mathrm{H} 5 \mathrm{~b}$ & $\mathrm{LP} \rightarrow \mathrm{COOP}$ & - & - & Supported \\
$\mathrm{H} 6 \mathrm{a}$ & $\mathrm{RFP} \rightarrow \mathrm{COOR}$ & - & + & Not supported \\
$\mathrm{H} 6 \mathrm{~b}$ & $\mathrm{RFP} \rightarrow \mathrm{COOP}$ & + & Supported
\end{tabular}

Source: own calculations. Hypotheses which turned insignificant according to the results of $t$-statistics and, therefore, should not be considered as reliable are marked italic

Abbreviations: COOR coordination, COOP cooperation, CP coercive power, RWP reward power, EP expert power, IP informational power, $L P$ legitimate power, RFP referent power 
reservations, based on our empirical results, we do not advise managers to apply coercive power.

According to our assumptions, reward power should have a negative effect on cooperation and a positive effect on coordination. The results show that our assumptions about the hypothesized effects of reward power on coordination as well as on cooperation were correct. In general, we observed that the use of this type of power provokes changes in behavior and motivates the target of influence to act according to the will of the influencing party. Therefore, it is highly recommended to apply reward power for improving both coordination and cooperation.

The use of expert power turned out to have a positive effect on coordination as well as on cooperation despite being considered less flexible and unrelated to specific performance from the theoretical point of view. The results are in line with Busch and Wilson (1976). They show that in particular, expertise is essential for building trust in buyer-supplier dyads. Overall, expert power has had relatively strong effects on cooperation as well as on coordination; thus, we recommend to use this type of power as often as possible.

The effects of informational power are similar to the effects of expert power, though the effect in the case of informational power on cooperation is much weaker than that of expert power. Similar results have been obtained by Eyuboglu and Atac (1991) who concluded that informational power could serve as a superior means for increased control distribution channels. In our in-depth survey, the experts have revealed similar insights. However, the interviewed experts have been rather hesitant regarding the possibility of using informational power in business reality.

According to our findings, the effects of legitimate power turned out to be positive for coordination and negative for cooperation. One must admit, though, that in spite of the positive sign of the effect on coordination, the strength of this effect turned out to be quite weak. Our expert interviews revealed that on the one hand, as long as all chain participants perceive the legitimate position as fairly obtained, legitimate power can be regarded as a very positive means for supply chain management. However, on the other hand, if the other participants perceive the position as unfairly obtained, it can be just the opposite.

Referent power turned out to have a positive effect on both coordination and cooperation. Because referent power stems from image and reputation, it is evident that the strength of the motivation to comply with this type of power would be based on the strength of the image and attractiveness of the relationship. An explanation might be that image and status symbols are highly valued in Russian culture (Hofstede and Hofstede 2005). A similar example has been shown for the Ukraine agri-food business. Suppliers of well-known foreign processors and retailers had fewer problems obtaining loans at more favorable interest rates because to some extent, doing business with a foreigner was regarded as a kind of status symbol (Gagalyuk and Hanf 2009). Taking into account the discussed issues, the use of referent power is highly advisable.

\section{Conclusions}

Although power relationships are beginning to receive more attention from researchers, only a few scientific works have studied power in the context of supply chain. In this context, power represents one of the major elements of the supply chain management. 
By analyzing the different sources of power (coercive, reward, expert, legitimate, referent, informational), we have also confirmed that these sources can be grouped as coercive and non-coercive. Using this classification, we have conducted a literature overview on power effects and have found that power has many multifaceted effects on coordination and cooperation in supply chain relationships.

We worked out and tested a theoretical model of the effects of power on cooperation and coordination and discuss possible managerial implications of using power as an effective tool for promoting SCM. To verify our research hypotheses, we conducted 89 semi-structured, in-depth, expert interviews via telephone about relationships of international food processing companies with their suppliers in Russia and tested the model using the partial least squares (PLS) approach.

Our main results can be summarized as follows. In spite of our assumption that coercive power can be seen to bring order and discipline into the relationship as well as be effective in changing behavior, the effects of coercive power turned out to be negative on both coordination and cooperation. According to our assumptions, reward power should have a negative effect on cooperation and a positive effect on coordination. Expert power turned out to have positive effects on coordination and cooperation. The effects of informational power are similar to the effects of expert power, though the effect in the case of informational power on cooperation is much weaker than that of expert power. According to the findings, the effects of legitimate power turned out to be positive for coordination and negative for cooperation. One must admit, though, that in spite of the positive sign of the effect on coordination, the strength of this effect turned out to be weak. Referent power turned out to have a positive effect on both coordination and cooperation.

\section{Endnotes}

${ }^{1}$ However, many authors who have studied power agree that there seems to be a problem in defining it (Bierstedt 1950). Having examined the different perspectives of power, we conclude that its definitions in different sciences resemble each other with a difference of the context in which it is applied (Cook and Emerson 1978; Cox 2004; Cox et al. 2004; Ireland 1999). One point is clear: the one who possesses power over another possesses the ability to cause that party to do something that it would not otherwise have done. We conclude that power generally refers to the ability, capacity, or potential to get others to do something; to command; to influence; to determine; or to control the behaviors, intentions, decisions, or actions of others in the pursuit of one's own goals or interests despite resistance, as well as to induce changes.

${ }^{2}$ These bases can also be dichotomized into coercive and non-coercive power (Hunt and Nevin 1974).

${ }^{3}$ Because the group of retailers was quite small, we were able to conduct only eight interviews with them. For model assessment, we deleted retailers from the sample to sustain the homogeneity of the units of analysis and avoid biased results. Therefore, the response rate represented $8.9 \%$. 
Authors' contributions

Both authors read and approved the final manuscript.

Competing interests

The authors declare that they have no competing interests.

\section{Author details}

${ }^{1}$ Thünen Institute, Braunschweig, Germany. ${ }^{2}$ Geisenheim University, Geisenheim, Germany.

Received: 12 May 2015 Accepted: 4 August 2016

Published online: 19 August 2016

\section{References}

Bachmann R (2001) Trust, power and control in trans-organizational relations. Organ Stud 22(2):337-365

Baldwin DA (1971) The power of positive sanctions. World Politics 24:19-38

Bannister E (1969) Sociodynamics: an integrative theorem of power, authority, influence, and love. Am Sociol Rev 34:374-393

Beier FJ, Stern LW (1969) Power in the distribution channel. In: Stern LW (ed) Distribution channels: behavioral dimensions. Houghton Mifflin, Boston, MA, pp 92-116

Belaya V, Hanf JH (2010) Foreign direct investment as an agent of change for Russian agrifood business—consequences of the export of chain management concepts by foreign investors. Post-Communist Econ 22(1):55-73

Belaya V, Hanf JH (2012) Managing Russian agri-food supply chain networks with power. J Chain Netw Sci 12(3):215-230

Belaya B, Török T, Hanf JH (2015) Does power oppose trust? The implications for supply chain management. In: Campbell CL (ed) Marketing in transition: scarcity, globalism, \& sustainability. Springer, Heidelberg, pp 55-59

Bierstedt R (1950) An analysis of social power. Am Sociol Rev 15:730-738

Blankertz L (1998) The value and practicality of deliberate sampling for heterogeneity: a critical multiplist perspective. Am J Eval 19(3):307-324

Blau P (1964) Exchange and power in social life. John Wiley, New York, p 117

Boyce RR, Brown TC, McClelland GH, Peterson GL, Schulze WD (1992) An experimental examination of intrinsic values as a source of the WTA-WTP disparity. Am Econ Rev 82(5):1366-1373

Boyle B, Dwyer FR, Robicheaux RA, Simpson JT (1992) Influence strategies in marketing channels: measures and use in different relationship structures. J Mark Res 29(November):462-473

Bretherton P, Carswell P (2002) Trust me-I'm a marketing academic!: a cross-disciplinary look at trust. In: Proceedings of the Academy of Marketing Annual Conference. Nottingham University Business School, United Kingdom

Busch P, Wilson DT (1976) An experimental analysis of a salesman's expert and referent bases of social power in the buyer-seller dyad. J Mark Res 13(1):3-11

Carlsmith KM (2006) The roles of retribution and utility in determining punishment. J Exp Soc Psychol 42:437-451

Carlsmith KM, Darley JM, Robinson P (2002) Why do we punish? Deterrence and just deserts as motives for punishment. J Pers Soc Psychol 83(2):284-299

Chatziaslan, L, Breen L and Webster M (2005) An analysis of power in buyer-supplier relationships in the pharmaceutical supply network in the UK National Health Service and its application to international markets. Working Paper. No 05/22, June 2005. University of Bradford

Chin WW (1998) The partial least squares approach to structural equation modelling. In: Marcoulides GA (ed) Modern methods for business research. Lawrence Erlbaum Associates, Mahwah, pp 295-358

Clemons EK, Row MC (1993) Limits to interfirm coordination through information technology: results of a field study in consumer packaged goods distribution. J Manag Inf 10(1):73-95

Coleman J (1990) Foundations of social theory. The Belknap Press, Cambridge

Condliffe JB (1944) Economic power as an instrument of national policy. Am Econ Rev 34(1):305-314

Cook KS, Emerson RM (1978) Power, equity and commitment in exchange networks. Am Sociol Rev 43(1):721-739

Cousins PD, Presses Universitaires de Grenoble (2002) Evaluer la perfromance des supply chains: mise au point. In, Castagnos, Jean-Claude and Retour, Didier (eds.) Le management des achats. Presses Universitaires de Grenoble, France, p 111-128

Cox A (2001a) Understanding buyer and supplier power: a framework for procurement and supply competence. J Supply Chain Manag 37(2):8-15

Cox A (2001b) Managing with power: strategies for improving value appropriation from supply relationships. J Supply Chain Manag 37(2):42-47

Cox A (2004) The art of the possible: relationship management in power regimes and supply chains. Supply Chain Manag 9(5):346-356

Cox A, Watson G, Lonsdale C, Sanderson J (2004) Managing appropriately in power regimes: relationship and performance management in 12 supply chain cases. Supply Chain Manag 9(5):357-371

Craig DR, Gabler WK (1963) The competitive struggle for market control. In: Westing JE (ed) Readings in marketing. Prentice Hall, Englewood Cliffs

Dapiran GP, Hogarth-Scott S (2003) Are co-operation and trust being confused with power? An analysis of food retailing in Australia and the UK. Int J Retail Distrib Manag 31(5):256-267

Davies B, Blackstock K, Brown K, Shannon P (2004) Challenges in creating local agri-environmental cooperation action amongst farmers and other stakeholders. Final Report of Scottish Executive Environment and Rural Affairs Department, Aberdeen

Doney PM, Cannon JP (1997) An examination of the nature of trust in buyer-seller relationships. J Mark 61:35-51

Dore R (1983) Goodwill and the spirit of market capitalism. Br J Sociol 34:459-482

Duke R (1998) A model of buyer-supplier interaction in UK grocery retailing. J Retail Consum Serv 5(2):93-103

Dwyer FR, Schurr PH, Oh S (1987) Developing buyer-seller relationships. J Mark 51:11-27 
El-Ansary AL, Stern LW (1972) Power measurement in the distribution channel. J Mark Res 9(1):47-52

Ellram LM, Cooper MC (1990) Supply chain management, partnership, and the shipper-third party relationship. Int J Logist Manag 1(2):1-10

Etgar M (1976) Channel domination and countervailing power in distribution channels. J Mark Res 13(8):254-262

Etgar M (1978) Selection of an effective channel control mix. J Mark 42(7):53-57

Eyuboglu N, Atac OA (1991) Informational power: a means for increased control in channels of distribution. Psychol Mark 8(3):197-213

Falk A, Fehr E, Fischbacher U (2005) Notes and comments-driving forces behind informal sanctions. Econometrica 73(6):2017-2030

Fehr E, Gächter S (2000) Cooperation and punishment in public goods experiments. Am Econ Rev 90(4):980-994

Fehr E, Gächter S (2002) Altruistic punishment in humans. Nature 415:137-140

Fornell C, Larcker DF (1981) Evaluating structural equation models with unobservable variables and measurement error J Mark Res 18(2):39-50

Frazier GL, Antia KD (1995) Exchange relationships and interfirm power in channels of distribution. J Acad Mark Sc 23:321-326

Frazier GL, Summers JO (1984) Interfirm influence strategies and their application within distribution channels. J Mark 48(3):43-55

French JRP, Raven B (1959) The bases of social power. In: Cartwright D (ed) Studies in social power. University of Michigan Press, Ann Arbor, pp 150-167

Fritsch N (2007) Erfolgsfaktoren im Stiftungsmanagement, Erfolgsfaktorenforschung im Nonprofit-Sektor. Gabler, Wiesbaden

Gagalyuk T, Hanf JH (2009) Impact of retail internationalization on East-European business environment: the case of Ukrainian agribusiness. J East-west Bus 15(1):96-118

Gagalyuk T, Hanf JH, Hingley M (2013) Firm and whole chain success?: network management in the Ukrainian food industry. J Chain Netw Sci 13(1):47-70

Ganesan S (1994) Determinants of long-term orientation in buyer-seller relationships. J Mark 58(4):1-19

Gardner GT, Stern PC (1996) Environmental problems and human behavior. Allyn and Bacon, Needham Heights

Gaski JF (1984) The theory of power and conflict in channels of distribution. J Mark 48:9-29

Gaski JF (1986) The theory of power and conflict in channels of distribution. J Mark 48(3):9-29

Gaski JF, Nevin JR (1985) The differential effects of exercised and unexercised power sources in a marketing channel. J Mark Res 22(2):130-142

Gellynck X, Kühne B, Weaver RD (2011) Relationship quality and innovation capacity of chains: the case of the traditional food sector in the EU. Int J Food Syst Dyn 2(1):1-22

Giebels E, De Dreu CKW, van de Vliert E (1998) The alternative negotiator as the invisible third at the table: the impact of potency information. Int J Confl Manag 9:5-21

Goldsmith K and Dhar R (2013) Negativity bias and task motivation: testing the effectiveness of positively versus negatively framed incentives. J Exp Psychol: Applied. Advance online publication doi:10.1037/a0034415

Gulati R (1995) Does familiarity breed trust? The implications of repeated ties for contractual choice in alliances. Acad Manag J 38:85-112

Guzman RA, Rodriguez-Sickert C, Rowthorn R (2007) When in Rome, do as the Romans do: the coevolution of altruistic punishment, conformist learning, and cooperation. Evol Hum Behav 28:112-117

Hair JF, Black WC, Babin BJ, Anderson RE, Tatham RL (2006) Multivariate data analysis, 6th edn. Prentice Hall, Upper Sadle River

Hamner WC, Organ DW (1978) Organizational behavior: an applied psychological approach. Business Publications, Inc, Dallas

Hanf JH, Dautzenberg K (2006) A theoretical framework of chain management. J Chain Netw Sci 6(2):79-94

Hingley M (2005) Power to all our friends? Learning to live with imbalance in UK supplier-retailer relationships. Ind Mark Manag 34(8):848-858

Hofstede G (2001) Culture's consequences: comparing values, behaviors, institutions, and organizations across nations, 2nd edn. Sage Publications, Thousand Oaks

Hofstede G, Hofstede GJ (2005) Cultures and organizations: software of the mind, 2nd edn. McGraw-Hill, New York

Hunt SD, Nevin JR (1974) Power in a channel of distribution: sources and consequences. J Mark Res 11(2):186-193

Ireland P (1999) Satisfying dependent customers: on the power of suppliers in IT systems integration supply chains. Supply Chain Manag 4(4):184-191

Ireland RD, Webb JW (2007) A multi-theoretic perspective on trust and power in strategic supply chains. Ind Mark Manag 36:482-497

Jap SD, Ganesan S (2000) Control mechanisms and the relationship life cycle: implications for safeguarding specific investments and developing commitment. J Mark Res 37(2):227-245

Johnsen RE and Ford D (2001) Asymmetrical and symmetrical customer-supplier relationships: contrasts, evolution and strategy, 17th Annual IMP Conference, September 7th-9th, Norwegian School of Management (BI), Oslo

Jones G, George J (1998) The experience and evolution of trust: implications for cooperation and teamwork. Acad Manag Rev 23(3):531-548

Kadochnikov S (2004) Pryamyezarubeshnyeinvestitsii v sovremennoiteoriiinstotutsyonalnoyekonomiki I teoriimeshdunarodnoytorgovli: osnovnyepodhody I empiricheskiyanaliz. Ural University, Ekaterinburg

Kalafatis SP (2000) Buyer-seller relationships along channels of distribution. Ind Mark Manag 31:215-228

Kähkönen, Anni-Kaisa (2014) The influence of power on the depth of collaboration » Supply Chain Management: An International Journal 19(1):17-30

Kumar N (2005) The power of power in supplier-retailer relationships. Ind Mark Manag 34:863-866

Kumar N, Scheer LK, Steenkamp J-BEM (1995) The effects of supplier fairness on vulnerable resellers. J Mark Res 32:54-65

Kumar N, Scheer LK, Steenkamp J-BEM (1998) Interdependence, punitive capability, and the reciprocation of punitive actions in channel relationships. J Mark Res 35:225-235 
Lee DY (2001) Power, conflict, and satisfaction in IJV supplier-Chinese distributor channels. J Bus Res 52:149-60 Lee KL, Low GT (2008) The exercise of social power and the effect of ethnicity: evidence from Malaysian's industrial companies. Int Bus Res 1(2):53-65

Lee HL, Padmanabhan V, Whang S (1997) Information distortion supply chain: the bullwhip effect. Manag Sci 43(4):546-558

Liu H, Wang YP (2000) Interfirm channel relationships, influence strategies and performance in China: an empirical examination. In: Becker K (ed) Culture and international business. The Haworth Press, Inc, United States

Lusch RF (1976) Sources of power: their impact on intrachannel conflict. J Mark Res 13(4):382-390

Lusch RF (1977) Franchisee satisfaction: causes and consequences. Int J Phys Distrib 7:7

Lusch RF, Brown JR (1996) Interdependency, contracting, and relational behavior in marketing channels. J Mark 60(10):19-38

Maloni MJ, Benton WC (1997) Supply chain partnerships: opportunities for operations research. Eur J Oper Res 101(3):419-429

Maloni MJ, Benton WC (2000) Power influences in the supply chain. J Bus Logist 21(1):49-73

Martinez-Ruiz A, Aluja-Banet T (2009) Toward the definition of a structural equation model of patent value: PLS path modeling with formative constructs. REVSTAT Statistical Journal 7(3):265-290

Mentzer JT, DeWitt W, Keebler JS, Min S, Nix NW, Smith CD, Zacharia ZG (2001) Defining supply chain management. Journal of Business Logistics 22(2):1-25

Merkens H (2000) Auswahlverfahren, Sampling, Fallkonstruktion. In: Flick U, von Kardorff E, Steinke I (eds) Qualitative Forschung - Ein Handbuch. Reinbekbei Hamburg, Rowohlt, Germany

Mohr JJ, Fisher RJ, Nevin JR (1996) Collaborative communication in interfirm relationships: moderating effects of integration and control. J Mark 60(3):103-115

Naudé P, Buttle F (2000) Assessing relationship quality. Ind Mark Manag 29:351-361

Patton MQ (1990) Qualitative evaluation and research methods, 2nd edn. Sage, Newbury Park

Payan JM, McFarland RG (2005) Decomposing influence strategies: argument structure and dependence as determinants of the effectiveness of influence strategies in gaining channel member compliance. J Mark 69(3):66-79

Perrow C (1970) Organizational analysis: a sociological view. Belmont, Wadsworth

Raven BH, Kruglanski AW (1970) Control and power. In: Swingle P (ed) The structure of conflict. Academic, New York, pp 69-109

Reve T, Stern L (1979) Interorganizational relations in marketing channels. Acad Manag Rev 4(3):405-16

Ringle CM, Wende S, Will A (2005) SmartPLS 2.0 M3. available at http://www.smartpls.de

Robicheaux RA, El-Ansary Al (1975) A general model for understanding channel member behavior. Journal of Retailing 52(4):13-30

Rokkan AL, Haugland SA (2002) Developing relational exchange: effectiveness and power. Eur J Mark 36(1):211-230

Sibley SD, Michie DA (1981) Distribution performance and power sources. Ind Mark Manag 10:59-65

Skinner SJ, GassenheimerJ B, Kelley SW (1992) Cooperation in supplier dealer relations. Journal of Retailing 68(2):174-193

Sodano V (2006) A power-based approach to the analysis of the food system. In: Bijman J, Omta SWF, Trienekens JH (eds) International agri-food chains and networks. Wageningen Academic Publishers, Wageningen, pp 199-215

Stern LW, El-Ansary Al (1992) Marketing channels, 4th edn. Prentice-Hall, Englewood Cliffs

Stern LW, Heskett JL (1969) Conflict management in interorganization relations: a conceptual framework. In: Stem L (ed) Distribution channels: behavioral dimensions. Houghton-Mifflin Company, Boston

Stern LW, Reve T (1980) Distribution channels as political economies. A framework for comparative analysis. J Mark 44(2):52-64

Stolte JF, Emerson RM (1976) Structural inequality: position and power in network structures. In: Hamblin R, Kunkel J (eds) Behavior theory in sociology. Trans-Action, New York, pp 131-149

Thompson JD (1967) Organizations in action. McGraw-Hill, New York

Walter T (2011) Vergeltung als Strafzweck, Prävention und Resozialisierung als Pflichten der Kriminalpolitik. Zeitschrift für Internationale Strafrechtsdogmatik 6(7):636-647

Wilkinson IF (1973) Power in distribution channels. Cranfield Research Monograph, Cranfield School of Management, Cranfield

Wilkinson IF (1979) Power and satisfaction in channels of distribution. Journal of Retailing 55(2):79-94

Wilkinson IF (1981) Power, conflict and satisfaction in distribution channels: an empirical study. Int J Phys Distrib Mater Manag 11:20-30

Zhao X, Xie J, Zhang W (2002) The impact of information sharing and ordering coordination on supply chain performance. Supply Chain Manag 7(1):24-40

Zhao X, Huo B, Flynn BB, Yeung JHY (2007) Impact of power and relationship commitment on manufacturer-customer integration in a supply chain. In: Proceedings of the Academy of Management Conference

Zhao X, Huo B, Flynn BB, Yeung JHY (2008) The impact of power and relationship commitment on the integration between manufacturers and customers in a supply chain. J Oper Manag 26:368-388 